\title{
The ATPase activity of molecular chaperone HSP60 is inhibited by immunosuppressant mizoribine
}

\author{
Masako Tanabe ${ }^{1}$, Ryuichi Ishida ${ }^{1}$, Fumiko Izuhara ${ }^{1}$, Atsushi Komatsuda ${ }^{2}$, Hideki Wakui ${ }^{2}$, \\ Kenichi Sawada ${ }^{2}$, Michiro Otaka ${ }^{3}$, Nobuhiro Nakamura ${ }^{4}$, Hideaki Itoh ${ }^{1^{*}}$ \\ ${ }^{1}$ Department of Life Science, Graduate School and Faculty of Engineering and Resource Science, Akita University, Akita, Japan \\ ${ }^{2}$ Department of Hematology, Nephrology, and Rheumatology, Akita University Graduate School of Medicine, Akita, Japan \\ ${ }^{3}$ Department of Gastroenterology, Juntendo University School of Medicine, Tokyo, Japan \\ ${ }^{4}$ Department of Molecular Biosciences, Faculty of Life Sciences, Kyoto Sangyo University, Kamigamo, Kyoto, Japan \\ Email: ${ }^{*}$ itohh@ipc.akita-u.ac.jp
}

Received 10 January 2012; revised 9 February 2012; accepted 21 February 2012

\begin{abstract}
The molecular chaperone HSP60 is a chaperonin homolog of GroEL. We had previously shown that the immunosuppressant mizoribine is bound directly to HSP60 and inhibited its chaperone activity. However, the inhibitory mechanisms of HSP60 by mizoribine have not yet been fully understood. In the present study, we investigated the influence of mizoribine on a folding cycle of HSP60 and co-chaperone HSP10. Our results showed that mizoribine inhibited the folding cycle of HSP60/HSP10. The ATPase activity of HSP60/HSP10 was decreased in the presence of mizoribine and the dissociation of HSP10 from HSP60 was also decreased by mizoribine. The same functions of GroEL and/or GroES were slightly affected by mizoribine. Based on our findings, we discuss the inhibitory mechanisms of HSP60 by mizoribine.
\end{abstract}

Keywords: HSP60; GroEL; Mizoribine; Inhibition Mechanisms; Conformational Change

\section{INTRODUCTION}

The bacterial chaperonin, GroEL, forms two large rings arranged back-to-back and each ring consists of heptameric 57-kDa subunits. GroEL interacts with cochaperone GroES, a single heptamer ring of 10-kDa subunits, in an ATP-dependent manner and forms an enclosed cavity with a hydrophilic wall chamber where folding of the non-native polypeptide substrate occurs [1-5]. GroEL forms a cylinder-like structure that is divided into three domains (apical, intermediate and equatorial domains). The apical domain is located at the entrance of the cylinder and binds GroES and substrate proteins using hydrophobic surfaces [6,7]. The equatorial domain hydrolyzes ATP, and the intermediate domain connects the

${ }^{*}$ Corresponding author. apical domain and the equatorial domain to produce a concerted movement of the GroEL subunit [8]. During the folding cycle of substrate proteins by GroEL, GroES and ATP bind to one of the two rings of the GroEL molecule, called the cis-ring, and form a bullet-type complex [9-13]. GroES and ATP cannot bind to the other ring, called the trans-ring, until the ATP is hydrolyzed. After the hydrolysis, the complexes are able to bind GroES and ATP at the trans-ring. GroES and ADP are released from the cis-ring, resulting in the ATP-bound bullet again. Thus, the folding cycle can be continued in a reciprocal manner.

HSP60 is a molecular chaperone and chaperonin homolog of GroEL, and HSP10 is a cochaperone homolog of GroES [12]. HSP60 was found in the mammalian mitochondrial matrix as a Pl protein precursor [14-16]. We have previously reported that mammalian HSP60 also existed in the cytoplasm and nucleus as well as in the mitochondria [17]. HSP60 plays an essential role in assisting with the folding of the newly synthesized polypeptides and refolding of the denatured proteins in the cells [14-17]. It has been reported that HSP60 forms a single ring or double ring structure in the presence of ATP $[18$, 19].

Mizoribine (4-carbamoyl-1- $\beta$-D-ribofuranosylimidazolium-5-olatemonohydrate) is a novel purine synthesis inhibitor that was developed in Japan (Figure 1). Mizoribine is an imidazole nucleotide antibiotic isolated from Eupenicillium brefeldianum and was shown to exhibit cytotoxic effects in mammalian cells [20,21]. Mizoribine is an oral immunosuppressive agent approved in several countries for preventing rejection after renal transplantation, IgA nephropathy and rheumatoid arthritis [22]. Its therapeutic window is based on the trough concentrations staying at $\geq 0.5$, but $<3 \mu \mathrm{g} \cdot \mathrm{ml}^{-1}$. It has been postulated that as the renal function returns to normal, higher doses may be needed to maintain efficacy than the current cli- 


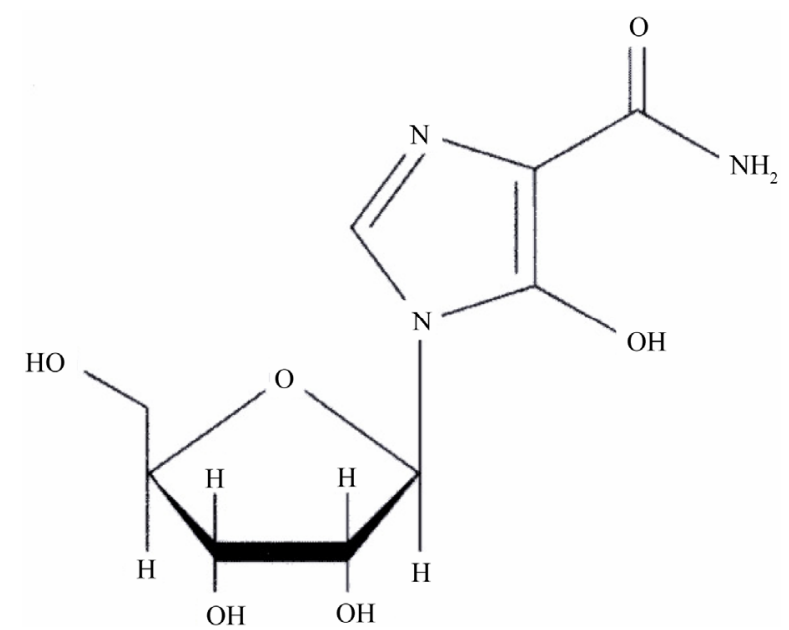

Figure 1. Chemical structure of mizoribine (molecular weight 259.22).

nical dosage of $2-5 \mathrm{mg} \cdot \mathrm{kg}^{-1} \cdot \mathrm{day}^{-1}$ [23] or $5-10 \mathrm{mg} / \mathrm{kg}$ per day (up to $500 \mathrm{mg}$ ) as a single daily dose on two days per week for over 24 months [24].

Previously, we found that a major protein was directly bound to mizoribine, and this protein was identified as HSP60 [25]. Additionally, we have shown that mizoribine inhibits the suppression of protein aggregation by HSP60 [25]. To understand, the detailed inhibition mechanisms of HSP60 by mizoribine in vitro, we analyzed the influence of mizoribine in three steps in a substrate folding cycle; i.e., binding of substrate, ATP hydrolysis and dissociation of HSP10.

In the present study, we found that mizoribine slows down the folding cycle, and the ATP hydrolysis or dissociation of cochaperone was also decreased by mizoribine. We discuss the role of the mizoribine-dependent inhibition in HSP60, and by comparing to the folding cycle of GroEL, we predict the inhibitory action of mizoribine on HSP60.

\section{MATERIALS AND METHODS}

\subsection{Plasmid Construction}

Human HSP60 and HSP10 cDNAs were amplified by PCR using specific primers. Human HSP60 and HSP10 cDNAs were subcloned into the NdeI/BamHI sites of pET-3a vector (Novagen, Madison, WI) by PCR with specific primers.

\subsection{Protein Purification}

Human HSP60 and HSP10 cDNAs were amplified by PCR using specific primers. HSP60 or HSP10 was expressed in Eschericha coli BL21 (DE3) pLysS. Cells were grown in LB medium supplemented with ampicillin and chloramphenicol at $37^{\circ} \mathrm{C}$. Expression of recombinant proteins was induced by addition of $0.1 \mathrm{mM}$ isopropyl-1thio- $\beta$-D-galactopyranoside. Cells were resuspended in buffer A (1 mM EDTA, $1 \mathrm{mM}$ DTT, 5\% grycerol and 10 $\mathrm{mM}$ Hepes-KOH [pH 7.4]) and lysed by sonication on ice. Supernatant was recovered after centrifugation $(20,000$ $\mathrm{rpm}, 15 \mathrm{~min}$ ) and fractionated by ammonium sulfate precipitation. Supernatant after $20 \%$ ammonium sulfate precipitation was applied to a Butyl 650M-Toyopearl column (Tosoh, Tokyo, Japan). After washing, proteins were eluted with a linear gradient of $20 \%$ - $0 \%$ ammonium sulfate in buffer A. Proteins were recovered by $60 \%$ ammonium sulfate precipitation from HSP60 rich fractions and dissolved in $0.1 \mathrm{M} \mathrm{NaCl} /$ buffer $\mathrm{A}$. The dissolved proteins were applied onto a Sephacryl S-300 column (GE Healthcare, Uppsala, Sweden). HSP60 fractions were recovered and applied onto Heparin Sepharose 6 Fast Flow column (GE Healthcare). After washing, proteins were eluted with a linear gradient of $0-0.1 \mathrm{M}$ $\mathrm{NaCl}$ in buffer A. HSP60 fractions were concentrated by ultrafiltration, and separated by a Superdex 200 10/300 GL column (GE Healthcare) equilibrated with $0.1 \mathrm{M}$ $\mathrm{NaCl} /$ buffer A. HSP60 fractions were concentrated, and buffer was exchanged with buffer B (10\% grycerol and $50 \mathrm{mM}$ Hepes-KOH [pH7.4]).

Similarly, precipitated proteins of HSP10 were dissolved and dialyzed against buffer C (1 mM EDTA and $10 \mathrm{mM}$ sodium acetate [pH 5.2]). After removal of insoluble fraction by centrifugation, proteins were applied to SP Sepharose Fast Flow column (GE Healthcare). After washing, proteins were eluted with a linear gradient of 0 - $0.7 \mathrm{M} \mathrm{NaCl}$ in buffer C. HSP10 fractions was concentrated by ultrafiltration, and buffer was exchanged with buffer B.

GroEL and GroES were expressed in E. coli cells and purified according to Motojima et al. [26]. GroEL and GroES were expressed in Eschericha coli AD21 carrying pKY206 groELS plasmid. Cells were grown in LB medium supplemented with tetracycline $(12.5 \mathrm{mg} / \mathrm{ml})$ and $0.2 \%$ glucose at $37^{\circ} \mathrm{C}$. Cells were lysed in buffer $\mathrm{A}$ by sonication, and extracted proteins were treated as described above until $60 \%$ ammonium sulfate precipitation was performed. After proteins were dissolved and dialyzed against buffer $\mathrm{C}$, protein samples were applied onto a Sephacryl S-300 column equilibrated with $0.1 \mathrm{M}$ $\mathrm{NaCl} /$ buffer A. GroEL fractions were concentrated, and buffer was exchanged with buffer B. GroES rich fractions were dialyzed against buffer $\mathrm{C}$, and insoluble fraction was removed by centrifugation $(20,000 \mathrm{rpm}, 15$ min). Proteins were applied to SP Sepharose Fast Flow column equilibrated with buffer C. After washing with $50 \mathrm{mM} \mathrm{NaCl}$ in buffer $\mathrm{C}$, proteins were eluted with a linear gradient of $0-0.7 \mathrm{M} \mathrm{NaCl}$ in buffer C. After GroES fractions were concentrated, and buffer was exchanged with buffer B. 


\subsection{Rhodanese Folding Assay}

Refolding assays of rhodanese were performed as previously reported $[8,27]$ with some modifications. Briefly, $25 \mu \mathrm{M}$ rhodanese from bovine liver (Sigma) was unfolded in $40 \mathrm{mM}$ HEPES-KOH buffer ( $\mathrm{pH} 7.4$ ), containing $6 \mathrm{M}$ guanidine hydrochloride and $1 \mathrm{mM}$ DTT at $25^{\circ} \mathrm{C}$ for $1 \mathrm{~h}$. The refolding reaction was started by a 500-fold dilution into buffer (50 mM HEPES-KOH [pH 7.4], containing $20 \mathrm{mM} \mathrm{KCl}, 10 \mathrm{mM} \mathrm{MgCl}_{2}$ ). The protein concentration of rhodanese during the refolding reaction was $0.25 \mu \mathrm{M}$ at $25^{\circ} \mathrm{C} ; 1.5$-fold molar excess of HSP60 and HSP10 relative to rhodanese were present in the refolding reaction in the presence or absence of mizoribine (Asahi Kasei Pharma Corporation). After 5 min incubation, ATP was added to a final concentration of $1 \mathrm{mM}$. At appropriate time points during the refolding reaction, $200 \mu \mathrm{L}$ of diluted enzyme solution added at the reaction solution consisted of $0.05 \mathrm{M} \mathrm{KCN}, 0.4 \mathrm{M} \mathrm{KH}_{2} \mathrm{PO}_{4}$ and $0.5 \mathrm{M} \mathrm{Na}_{2} \mathrm{~S}_{2} \mathrm{O}_{3}$. After the mixture was incubated for 9 min at room temperature and stopped by the addition of $2 \mathrm{ml}$ of buffer containing $1.5 \%$ formaldehyde, $10 \mathrm{~g}$ $\mathrm{Fe}\left(\mathrm{NO}_{3}\right)_{3} \cdot 9 \mathrm{H}_{2} \mathrm{O}$ in $13 \% \mathrm{HNO}_{3}$, and the activity measured by the absorbance at $460 \mathrm{~nm}$. Refolding yield was determined as the percentage ratio of the activity of the re- folding enzyme relative to that of native enzyme.

\subsection{Rhodanese Aggregation Assay}

Rhodanese aggregation was measured in the presence of HSP60/HSP10 or GroEL/GroES as described [25]. Briefly, $25 \mu \mathrm{M}$ rhodanese was unfolded in $40 \mathrm{mM}$ HEPES$\mathrm{KOH}$ buffer ( $\mathrm{pH} 7.4$ ), containing $6 \mathrm{M}$ guanidine hydrochloride and $1 \mathrm{mM}$ DTT at $25^{\circ} \mathrm{C}$ for $1 \mathrm{~h}$. Renaturation was initiated by diluting the deatured rhodanese 500-fold to a final concentration of $0.3 \mu \mathrm{M}$ into $50 \mathrm{mM}$ HEPES$\mathrm{KOH}$ buffer (pH 7.4), containing $10 \mathrm{mM} \mathrm{MgCl} 2,20 \mathrm{mM}$ $\mathrm{KCl}$ and $1 \mathrm{mM}$ ATP with $0-10 \mathrm{mM}$ mizoribine. The aggregation of denatured rhodanese was monitored by the absorbance at $320 \mathrm{~nm}$ with a HITACHI U-3900 spectrophotometer.

\subsection{Measurement of ATPase Activity}

$0.38 \mu \mathrm{M}$ HSP60/HSP10 was pre-incubated $5-10 \mathrm{mM}$ mizoribine in a buffer containing $1 \mathrm{mM}$ DTT, $10 \mathrm{mM}$ $\mathrm{MgCl}_{2}, 20 \mathrm{mM} \mathrm{KCl}, 25 \mathrm{mM}$ HEPES-KOH (pH 7.4) at $25^{\circ} \mathrm{C}$, for $5 \mathrm{~min}$. After pre-incubation, $1 \mathrm{mM} \mathrm{ATP} \mathrm{was}$ added and incubated for $60 \mathrm{~min}$ at $25^{\circ} \mathrm{C}$. The samples were transferred to a 96-well plate and BIOMOL GREEN (100 $\mu$ l) (Enzo Life Science, New York, USA) was added. The samples were incubated for $30 \mathrm{~min}$ at room temperature, and absorbance was measured at 650 $\mathrm{nm}$. The free phosphate concentration was calculated using the standard curve.

\subsection{Measurement of Protein Digestion}

$0.38 \mu \mathrm{M}$ HSP60/HSP10 or GroEL/GroES were preincubated with various $1 \mathrm{mM}$ nucleotides at $25^{\circ} \mathrm{C}$ for $10 \mathrm{~min}$. Protein samples were digested by $10 \mathrm{mg} / \mathrm{ml}$ trypsin at $25^{\circ} \mathrm{C}$ for $15 \mathrm{~min}$. Digestion reaction was stopped by adding SDS sample buffer and heating at $100^{\circ} \mathrm{C}$ for $3 \mathrm{~min}$. Digested proteins were separated by SDS-PAGE (12\% gel) and detected by Coomassie Brilliant Blue R-250 staining. Amount of trypsin-resistant HSP10 and GroES was quantified by the Image J program (National Institute of Health, Bethesda, MD) after scanning gel images.

\section{RESULTS}

\subsection{Mizoribine Inhibited Substrate Refolding by HSP60/HSP10}

First, to elucidate whether mizoribine inhibits the chaperonin-assisted folding of the substrate, we analyzed the refolding activity of HSP60/HSP10 or GroEL/GroES in the presence or absence of mizoribine. As the substrate protein, we used rhodanese whose folding depends on GroEL/GroES [28,29]. Denatured rhodanese was refolded by HSP60/HSP10 (Figure 2(a), solid circles) and GroEL/GroES (Figure 2(b), solid squares) in a time-dependent manner. However, in the presence of mizoribine, the rhodanese activity decreased in a concentration-dependent manner. In contrast, mizoribine only marginally affected the rhodanese activity recovery by GroEL/ GroES (Figure 2(c)). The rhodanese activity in HSP60/ HSP10 also gradually decreased after $20 \mathrm{~min}$ in the presence of $10 \mathrm{mM}$ mizoribine (Figure 2(a), open circles). These results suggested that mizoribine inhibited the folding cycle of HSP60/HSP10 in comparison to GroEL/ GroES.

\subsection{Mizoribine Led to Aggregation of Substrates}

Next, to verify whether the aggregation of the substrates is caused by mizoribine, we measured the rhodanese aggregation activity at $25^{\circ} \mathrm{C}$, and analyzed the data after 60 min. As shown in Figure 3, HSP60/HSP10 or GroEL/ GroES efficiently inhibited the aggregation of rhodanese. In contrast, the addition of mizoribine increased the aggregation of rhodanese in a dose dependent manner. Especially, the aggregation activity of HSP60/HSP10 increased about $26 \%$ in the presence of mizoribine. In addition, mizoribine had no effects on the aggregation of the native-formed substrate (data not shown). This result showed that the association between HSP60 and the substrate was prevented by mizoribine.

\subsection{Mizoribine Inhibited ATPase Activity of HSP60/HSP10}

As is well known, the ATPase activity is important in the 


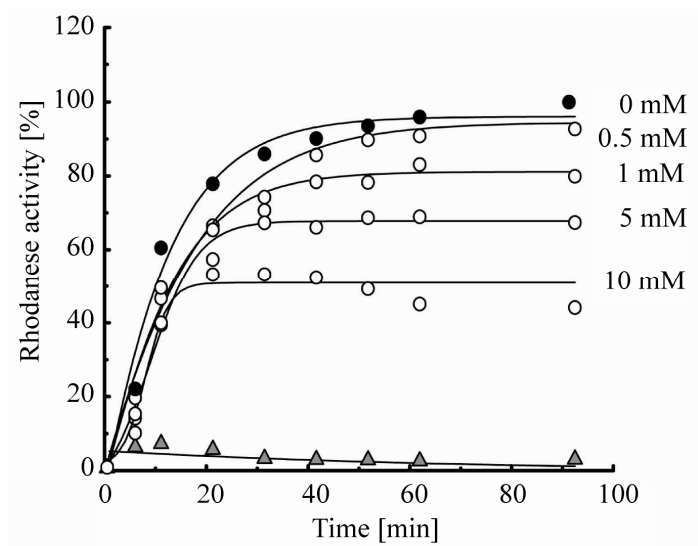

(a)

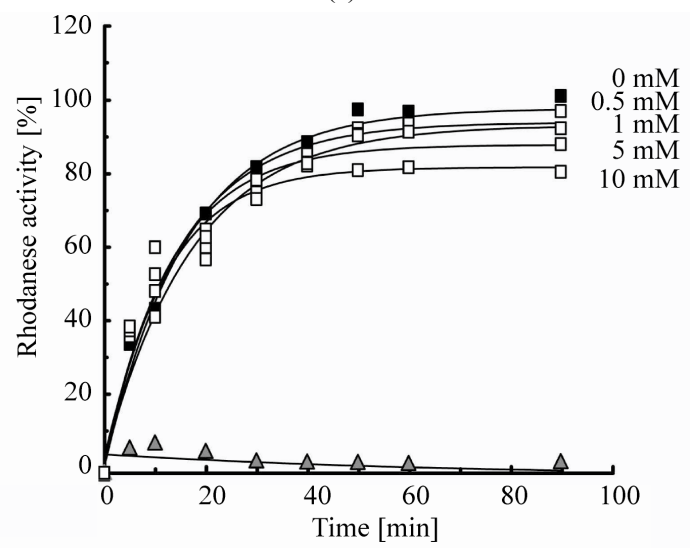

(b)

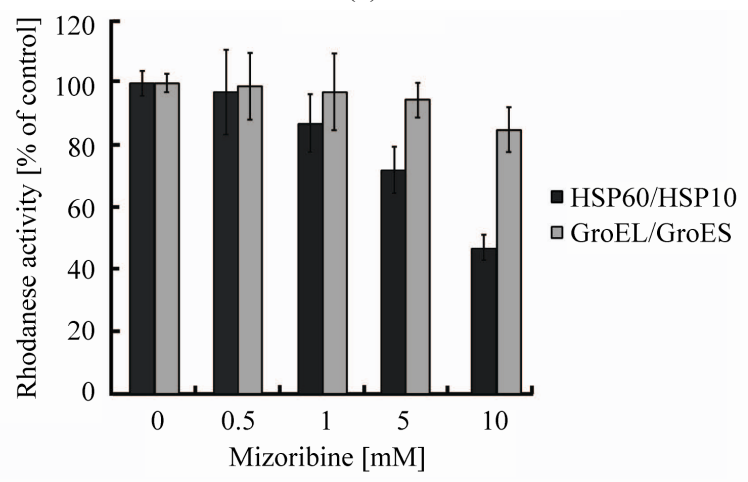

(c)

Figure 2. Rhodanese refolding activity is inhibited by mizoribine. (a) Time course of the HSP60/HSP10-assisted folding of rhodanese in the presence of four concentrations of mizoribine. Rhodanese activity in the presence or absence of mizoribine is shown by solid or open circles, respectively. Solid triangles represent spontaneous refolding; (b) Time course of the GroEL/ GroES-assisted folding of rhodanese using the same methods as (a). Rhodanese activity with and without mizoribine is shown by solid and open squares, respectively. Solid triangles represent spontaneous refolding; (c) Refolding activity after $60 \mathrm{~min}$ of the HSP60/HSP10 (black bars) or GroEL/GroES (grey bars)assisted folding of rhodanese in the presence of four concentrations of mizoribine. Amounts of rhodanese activity in the absence of mizoribine are set to the control $(100 \%)$. Mean and S.D. of at least three independent measurements are shown.

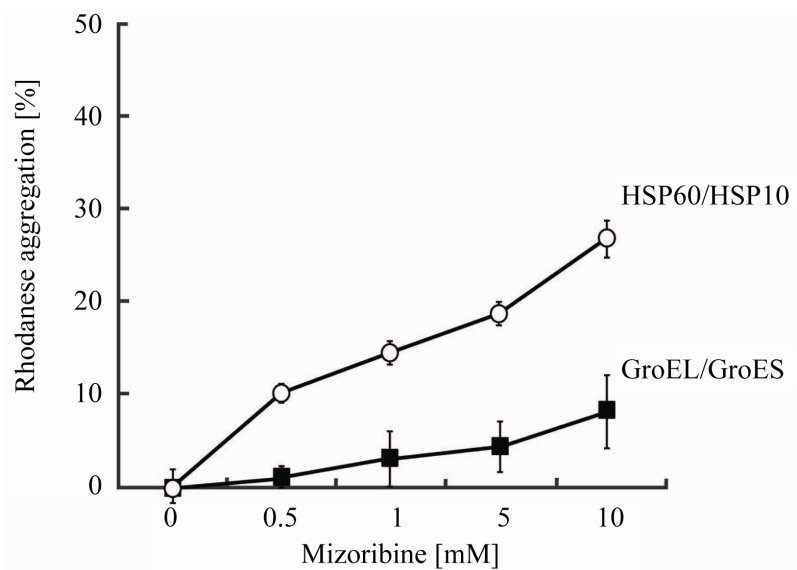

Figure 3. The aggregation prevention activity of HSP60 or GroEL is inhibited by mizoribine. Rhodanese was unfolded by $6 \mathrm{M}$ guanidine hydrochloride and diluted 500-fold into a buffer (50 mM HEPES-KOH buffer (pH 7.4), $10 \mathrm{mM} \mathrm{MgCl} 2,20 \mathrm{mM}$ $\mathrm{KCl}$ and $1 \mathrm{mM} \mathrm{ATP}$ ) and $0.37 \mathrm{mM} \mathrm{HSP60/HSP10}$ (open circles) or GroEL/GroES (solid squares) with four mizoribine concentrations at $25^{\circ} \mathrm{C}$. Aggregation activity after $60 \mathrm{~min}$ is set to the control $(100 \%)$. Mean of at least three independent measurements are shown.

chaperonin reaction cycle. To determine whether the ATP hydrolysis is inhibited by mizoribine, we measured the ATPase activity. The ATPase activity of HSP60/ HSP10 or GroEL/GroES was inhibited by mizoribine in a dose-dependent manner (Figure 4). The ATPase activity of HSP60/HSP 10 decreased about $30 \%$ under the highest concentration of mizoribine, while the ATPase activity of GroEL/GroES was marginally affected. The ATP-binding and hydrolysis triggered the release of the folding substrate protein and dissociation of cochaperone $[30,31]$. Therefore, it was thought that mizoribine has an effect on the release of the folding protein and the initiation of the next folding cycle.

\subsection{Mizoribine Inhibited ATP Hydrolysis Rate of HSP60/HSP10}

It is possible that mizoribine inhibits the ATPase activity of HSP60/HSP 10 by inhibiting the binding affinity of ATP to HSP60/HSP10. To assess this possibility, we measured whether mizoribine affected the kinetics of the ATPase activity of HSP60/HSP10 or GroEL/GroES in the presence or absence of mizoribine. We analyzed the Michaelis-Menten kinetics (michaelis constant $\left[k_{\mathrm{m}}\right]$ and catalytic rate constant $\left[k_{\text {cat }}\right]$ ) of the ATPase activity for various ATP concentrations. The $k_{\mathrm{m}}$ value of HSP60/ HSP10 was $4.27 \pm 0.65 \times 10^{-5} \mathrm{M}$, and $10 \mathrm{mM}$ mizoribine did not significantly affect it (Figure 5, solid circles). In contrast, the $k_{\text {cat }}$ value of HSP60/HSP10 was $0.63 \mathrm{~min}^{-1}$ and the presence of $10 \mathrm{mM}$ mizoribine significantly decreased it $\left(0.35 \mathrm{~min}^{-1}\right)$ (Figure 5, open circles. and Table 1). On the other hand, the $k_{\mathrm{m}}$ and $k_{\text {cat }}$ values of GroEL/ 


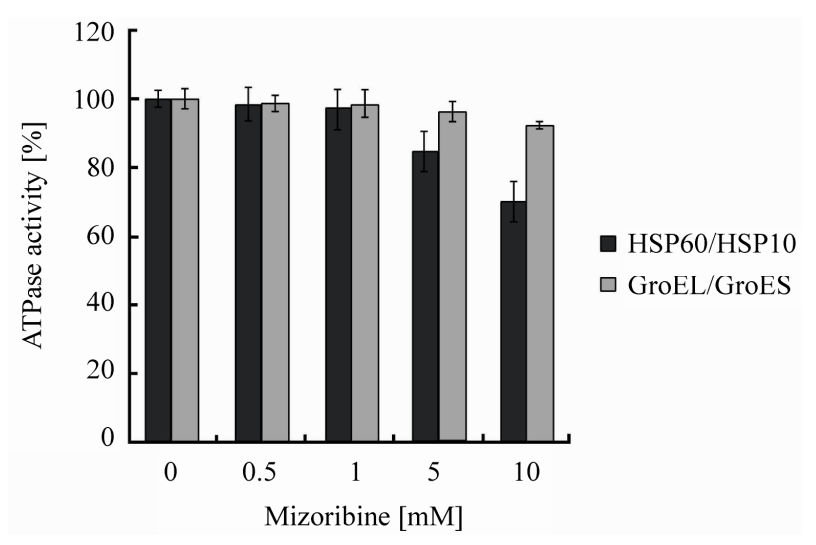

Figure 4. ATPase activity is inhibited by mizoribine in a dosedependent manner. HSP60/HSP10 (black bars) or GroEL/ GroES (gray bars) indicate ATPase activity after incubation for $60 \mathrm{~min}$ in the presence or absence of mizoribine. Mean and S.D. of at least three independent measurements are shown.

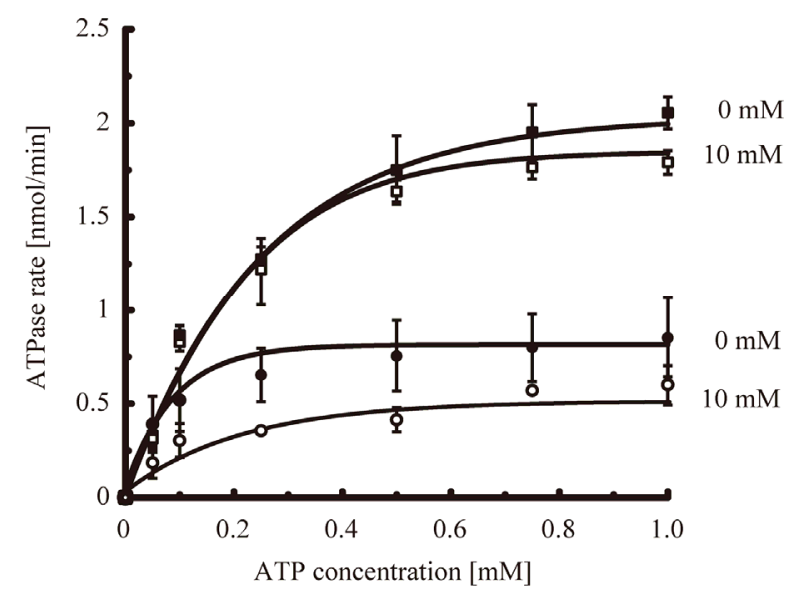

Figure 5. ATPase activity is decreased by mizoribine. ATPase activity of HSP60/HSP10 or GroEL/GroES in the presence of various concentrations of ATP. The solid circles and squares indicate HSP60/HSP10 and GroEL/GroES, respectively. The closed circles and squares indicate HSP60/HSP10 or GroEL/ GroES in the absence of mizoribine, respectively. The open circles and squares indicate HSP60/HSP10 and GroEL/GroES in the presence of $10 \mathrm{mM}$ mizoribine, respectively.

Table 1. The kinetics parameters for chaperonin-nucleotide interaction in the presence or absence of mizoribine. Michaelis constants $\left(k_{\mathrm{m}}\right)$ and molecular activity $\left(k_{\text {cat }}\right)$ for HSP60/HSP10 or GroEL/GroES were calculated using Origin 6.1 software. The addition of $10 \mathrm{mM}$ mizoribine is shown as Miz+. Data represent the mean \pm S.D. $(n=3$, independent experiment).

\begin{tabular}{ccc}
\hline & $k_{\mathrm{m}}[\mathrm{M}]$ & $k_{\text {cat }}\left[\mathrm{min}^{-1}\right]$ \\
\hline HSP60/HSP10 & $(4.27 \pm 0.65) \times 10^{-5}$ & 0.63 \\
HSP60/HSP10 ${ }^{\mathrm{Miz}+}$ & $(4.72 \pm 0.83) \times 10^{-5}$ & 0.35 \\
GroEL/GroES & $(30.3 \pm 7.30) \times 10^{-5}$ & 1.32 \\
GroEL/GroES & $(29.7 \pm 10.6) \times 10^{-5}$ & 1.28 \\
\hline
\end{tabular}

GroES were not significantly changed in the presence and absence of mizoribine (Figure 5, squares and Table 1). These results showed that mizoribine decreased the ATP hydrolysis rate but not the affinity of HSP60/ HSP10 and ATP.

\subsection{Mizoribine Decreased the Dissociative Reaction of Cochaperone HSP10 from HSP60}

The presented results clearly indicated that mizoribine inhibited the ATP hydrolysis rate of HSP60/HSP10. HSP10 repeatedly bound and dissociated from HSP60 coupled with the ATP hydrolysis of HSP60. To investigate whether the binding of HSP10 was affected by mizoribine, we performed a trypsin digestion experiment. When HSP60 is in a complex with HSP10, both HSP60 and HSP10 are resistant to the trypsin treatment. HSP60 and HSP10 become trypsin sensitive when the complex is dissociated. In the absence of mizoribine, significant amounts of HSP60 and HSP10 were decreased. In the presence of mizoribine, the degradation of HSP10 was significantly inhibited in a dose-dependent manner suggesting that the dissociation of HSP10 declined in the presence of mizoribine (Figures 6(a) and (c)). In contrast, GroEL and GroES were digested to a similar level in the presence and absence of mizoribine. These results suggested that the binding of GroEL and GroES were not significantly affected by mizoribine (Figures 6(b) and (c)). When similar experiments were performed in the absence of ATP, HSP10 was efficiently degraded by trypsin because it could not bind to HSP60 in the absence of ATP (data not shown). These results raised the possibility that mizoribine decreased the dissociation of HSP10 from HSP60 in the presence of ATP.

\section{DISCUSSIONS}

The evidence for an (auto) antigen-driven process at the sites of inflammation has come forward only recently. Molecular chaperones have been identified as playing either immunologically mediated disease promoting or protective roles. HSP60 has been shown to trigger innate and adaptive immune responses that initiate the earliest still reversible inflammatory stage of atherosclerosis [3235]. HSP60 is structurally highly conserved and abundantly expressed by prokaryotic and eukaryotic cells under stressful conditions. Beneficial protective immunity to microbial HSP60 acquired by infection or vaccination and bona fide autoimmunity to biochemically altered autologous HSP60 is present in all humans. In vitro and in vivo experiments have demonstrated that classical atherosclerosis risk factors can act as endothelial stressors that provoke the simultaneous expression of adhesion molecules and of HSP60 in mitochondria, in cytoplasm, 


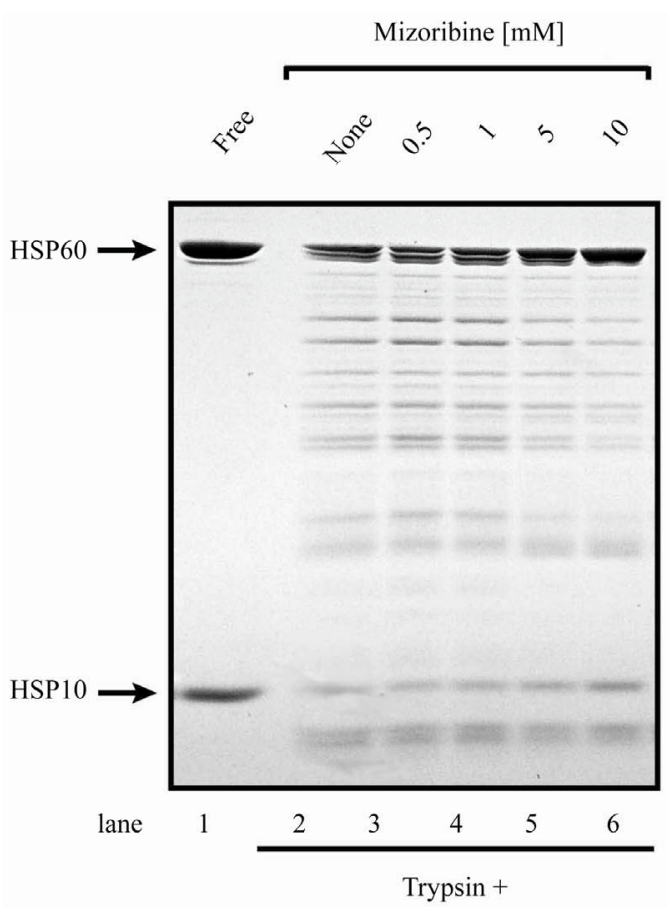

(a)

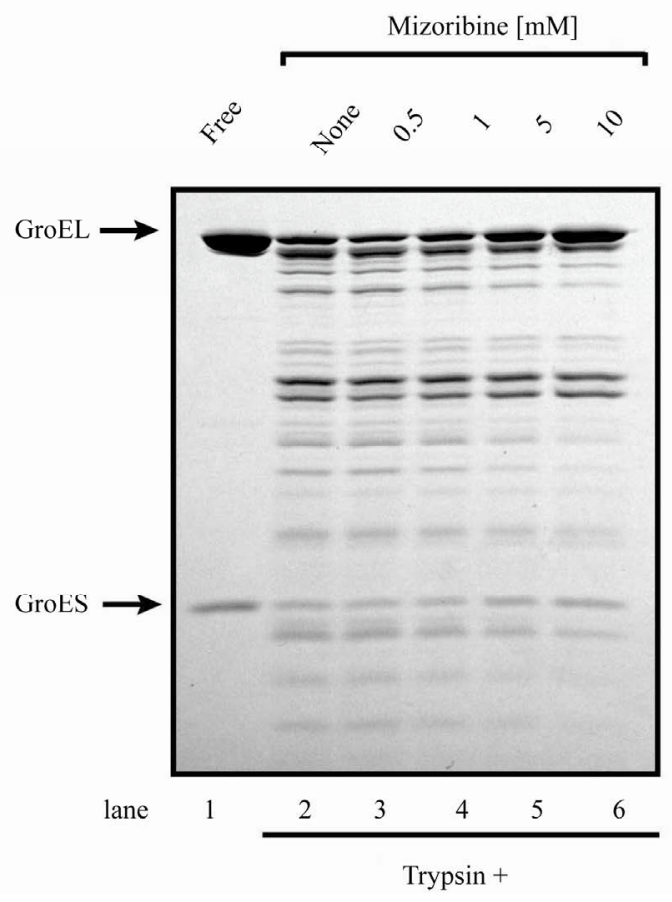

(b)

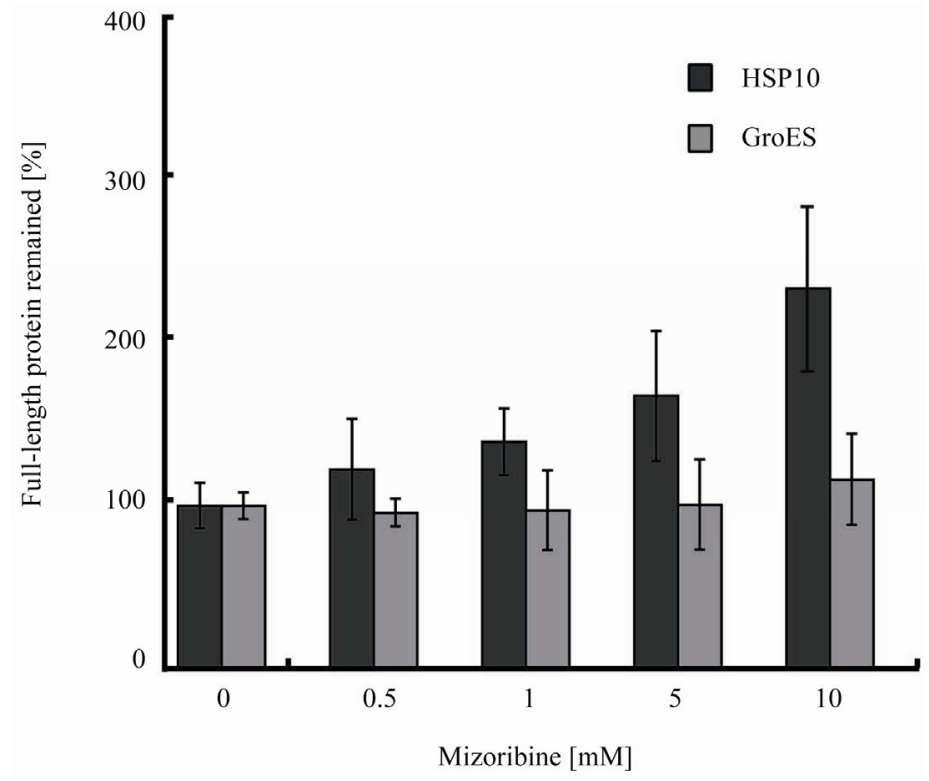

(c)

Figure 6. Chaperonin-dependent protease resistance of cochaperone is induced by high concentration of mizoribine. (a, b) Trypsin resistance of $1 \mu \mathrm{M}$ HSP60/HSP10 (a) or $1 \mu \mathrm{M}$ GroEL/GroES (b) in the presence of 1mM ATP and four concentrations of mizoribine. Digested samples were analyzed by SDS-PAGE. (a) Arrows indicate full-length HSP60 and HSP10 (lane 1), and with mizoribine (lanes 2-6); (b) Arrows indicate full-length GroEL and GroES (lane 1), and with mizoribine (lanes 2-6); (c) Band intensity of trypsin-resistant full-length HSP10 or GroES was quantified using Image $J(n=3)$.

and on the cell surface, where it acts as a "danger signal" for cellular and humoral immune reactions $[14,17,36]$. Hence, protective, preexisting anti-HSP60 immunity may have to be "paid for" by harmful (auto) immune crossreactive attack on arterial endothelial cells maltreated by atherosclerosis risk factors. These experimentally and clinically proven findings are the basis for the autoimmune concept of atherosclerosis.

It has been reported that a large subset of HSP60-reactive peripheral lymphoid gamma delta $\mathrm{T}$ cells preexists 
in normal adult mice, all members of which respond to a single segment of this common heat shock protein [37]. Gamma delta $T$ cells are a distinct lymphocyte population that can exhibit reactivity with heat shock proteins over-expressed at inflammatory sites. As gamma delta T cells may be involved in the central nervous system (CNS) inflammatory process in multiple sclerosis (MS). These cells that express the variable (V) gene segments $\mathrm{V}$ delta $1, \mathrm{~V}$ delta 2 , and $\mathrm{V}$ gamma 2 (V gamma 9) were found to accumulate in acute, demyelinating MS plaques and appeared to have undergone clonal expansion, most likely because of recognition of a specific CNS ligand. Further, $60-\mathrm{kDa}$ and $90-\mathrm{kDa}$ heat shock proteins (HSP60 and HSP90), which may be target antigens for autoreactive gamma delta $\mathrm{T}$ cells, were found to be expressed in normal CNS tissue and overexpressed in acute MS plaques. In acute plaques, HSP60 was found in foamy macrophages, while HSP90 was detected in reactive astrocytes. These results provide evidence for a role of gamma delta T cells in active stages of MS [38].

We previously demonstrated that mizoribine inhibited the chaperone activity, i.e., the anti-protein aggregation activity, of HSP60 [25]. In the present study, we found that mizoribine inhibited the folding activity of HSP60/ HSP10 (Figure 2). ATP is required for the GroEL/ES activation of the folding reaction [30]. The deletion of cooperative binding of ATP reduces the rate of productive folding [39]. Our results showed that the ATPase activity of HSP60/HSP10 was decreased by mizoribine (Figure 4). Thus, it is thought that the decrease in the folding activity of HSP60/HSP10 is relative to the decrease in the ATP hydrolysis. The ATP hydrolysis activity correlates with cochaperone [18,31]. Some studies suggested that the ATPase activity of GroEL is suppressed by the binding of GroES and stimulated by the substrate protein [40-42]. Our results found that the dissociation of HSP10 was inhibited by mizoribine (Figure 6). Therefore, we thought the increase in the binding of HSP60 and HSP10 is induced by the decrease in the ATPase activity. Moreover, this inhibition of the dissociation of HSP10 also affects the binding of the substrate. The GroES binding site mostly overlaps with the substrate protein binding site at the apical domain [26]. The GroEL mutations that lack the double open ring conformation can bind GroES, while the ATP hydrolysis cannot bind the substrate protein [42]. In contrast, our results suggested that the binding of the substrate protein to HSP60 was not trapped by mizoribine (Figure 2(c)). Thus, an increase in the binding of HSP10 forms a football complex, and the substrates cannot access this complex due to the full coverage of the binding sites by two HSP60 heptamers, therefore it is thought that the nonbinding substrates were aggregated (Figure 3).

Previous studies suggested that the conformational changes of each domain in GroEL were controlled by the binding and hydrolysis of ATP and GroES, which suggested that the communication network of each of the three domains was very important for the chaperonin mechanism [8,43-46]. The GroEL C138W was a GroEL mutant of the intermediate domains, and it formed a stable ternary complex in which GroES and denatured substrate proteins were coincidentally bound to GroEL [8, 47]. This ternary complex did not have any chaperonindependent folding activity and ATPase activity. Based on these reports, the inhibition of HSP60 by mizoribine was probably induced by the prevention of the communication signal (for example, the binding and hydrolysis of ATP and the binding of the substrate protein). This prevention of the communication signal allows the structure change in the domain of HSP60, so that it is likely that the ATPase activity declined, and the HSP10 formed a more stable complex with HSP60. In addition, we found that the inhibition of the chaperonin function of HSP60 by mizoribine was greater than that of GroEL. Since the sequence identity of HSP60 and GroEL was about $52 \%$ [17], conformational changes by mizoribine seem to be apparently different between HSP60 and GroEL.

In the present in vitro study using bacterially expressed proteins, we needed $5-10 \mathrm{mM}$ mizoribine to find its novel mechanisms on HSP60/HSP10. In our previous study, we showed that mizoribine affected the conformation of 14-3-3 proteins and enhanced the interaction between glucocorticoid receptor (GR) and 14-3-3n dose-dependently in vitro [48]. In transient transfection experiments using monkey kidney COS-7 cells, mizoribine enhanced the induction of GR activity by dexamethasone at a mizoribine concentration of $10 \mu \mathrm{M}$ (about $2.6 \mu \mathrm{g} / \mathrm{ml})$. This condition was considered physiologically relevant. However, in vitro pull-down experiments using bacterially expressed proteins and in conformational change analysis of 14-3-3 proteins, higher amounts of mizoribine were needed as in the present study. It is known that mizoribine has a very specific mechanism of action on lymphocytes that inhibits their proliferation without interfering with purine synthesis in other cell types [49]. Our findings provide new insights into other mechanisms of action of the immunosuppressant mizoribine.

In conclusion, we suggest that the reduction of the folding activity of HSP60 by mizoribine arises from a decrease in the ATPase activity of HSP60. Additionally, the inhibitory functions are found to be different between HSP60 and GroEL.

\section{ACKNOWLEDGEMENTS}

We thank Dr. H. Kubota (Akita University) for his useful advice and discussion. We are grateful to H. Takahashi, N. Sasaki and T. Okamoto 
for the protein preparations. This work was supported in part by a Grant-in-Aid for Scientific Research to H.I. (Exploratory Research: No. 16651056) from the Japanese Ministry of Education and Science, Sports and Culture.

\section{REFERENCES}

[1] Braig, K., Otwinowski, Z., Hegde, R., Boisvert, D.C., Joachimiak, A., Horwich, A.L. and Sigler, P.B. (1994) The crystal structure of the bacterial chaperonln GroEL at 2.8 Å. Nature, 371, 578-586. doi:10.1038/371578a0

[2] Lin, Z., Schwartz, F.P. and Eisenstein, E. (1995) The hydrophobic nature of GroEL-Substrate binding. The Journal of Biological Chemistry, 270, 1011-1014. doi:10.1074/jbc.270.3.1011

[3] Xu, Z., Horwich, A.L. and Sigler, P.B. (1997) The crystal structure of the asymmetric GroEL-GroES-(ADP) 7 chaperonin complex. Nature, 388, 741-750. doi:10.1038/41944

[4] Hartl, F.U. and Hayer-Hartl, M. (2002) Molecular chaperones in the cytosol: From nascent chain to folded protein. Science, 295, 1852-1858. doi:10.1126/science. 1068408

[5] Motojima, F., Chaudhry, C., Fenton, W.A., Farr, G.W. and Horwich, A.L. (2004) Substrate polypeptide presents a load on the apical domains of the chaperonin GroEL. Proceedings of the National Academy of Science of the USA, 101, 15005-15012. doi:10.1073/pnas.0406132101

[6] Langer, T., Pfeifer, G., Martin, J., Baumeister, W. and Hartl, F.U. (1992) Chaperonin-mediated protein folding: GroES binds to one end of the GroEL cylinder, which accommodates the protein substrate within its central cavity. The EMBO Journal, 11, 4757-4765.

[7] Ranson, N.A., Farr, G.W., Roseman, A.M., Gowen, B., Fenton, W.A., Horwich, A.L. and Saibil, H.R. (2001) ATP-bound states of GroEL captured by cryo-electron microscopy. Cell, 107, 869-879. doi:10.1016/S0092-8674(01)00617-1

[8] Kawata, Y., Kawagoe, M., Hongo, K., Miyazaki, T., Higurashi, T., Mizobata, T. and Nagai, J. (1999) Functional communications between the apical and equatorial domains of GroEL through the intermediate domain. Biochemistry, 38, 15731-15740. doi:10.1021/bi9909750

[9] Weissman, J.S., Rye, H.S., Fenton, W.A., Beechem, J.M. and Horwich, A.L. (1996) Characterization of the active intermediate of a GroEL-GroES-mediated protein folding reaction. Cell, 84, 481-490. doi:10.1016/S0092-8674(00)81293-3

[10] Behlke, J., Ristau, O. and Schönfeld, H.J. (1997) Nucleotide-dependent complex formation between the Escherichia coli chaperonins GroEL and GroES studied under equilibrium conditions. Biochemistry, 36, 5149-5156. doi:10.1021/bi962755h

[11] Ueno, T., Taguchi, H., Tadakuma, H., Yoshida, M. and Funatsu, T. (2004) GroEL mediates protein folding with a two successive timer mechanism. Molecular Cell, 14, 423-434. doi:10.1016/S1097-2765(04)00261-8

[12] Hartl, F.U. and Hayer-Hartl, M. (2009) Converging con- cepts of protein folding in Vitro and in Vivo. Nature Structural and Molecular Biology, 16, 574-581. doi:10.1038/nsmb.1591

[13] Horwich, A.L., Apetri, A.C. and Fenton, W.A. (2009) The GroEL/GroES cis cavity as a passive anti-aggregation device. FEBS Letters, 583, 2654-2662. doi:10.1016/j.febslet.2009.06.049

[14] Guputa, R. S., Venner, T. J. and Chopra, A. (1985) Genetic and biochemical studies with mutants of mammalian cells affected in microtubule-related proteins other than tubulin: Mitochondrial localization of a microtubule-related protein. Canadian Journal of Biochemistry and Cell Biology Revue, 63, 489-502.

[15] Picketts, D.J., Mayanil, C.S.K. and Guputa, R.S. (1989) Molecular cloning of a Chinese hamster mitochondrial protein related to the "chaperonin" family of bacterial and plant proteins. The Journal of Biological Chemistry, 264, 12001-12008.

[16] Singh, B., Patel, H.V., Ridley, R.G., Freeman, K.B. and Guputa, R.S. (1990) Mitochondrial import of the human chaperonin (HSP60) protein. Biochemical and Biophysical Research Communications, 169, 391-396. doi:10.1016/0006-291X(90)90344-M

[17] Itoh, H., Kobayashi, R., Wakui, H., Komatsuda, A., Ohtani, H., Miura, A.B., Otaka, M., Masamune, O., Andoh, H., Koyama, K., Sato, Y. and Tashima, Y. (1995) Mammalian $60-\mathrm{kDa}$ stress protein (chaperonin homolog). Identification, biochemical properties, and localization. The Journal of Biological Chemistry, 270, 13429-13435. doi:10.1074/jbc.270.22.13429

[18] Nielsen, K.L. and Cowan, N.J. (1998) A single ring is sufficient for productive chaperonin-mediated folding in Vivo. Molecular Cell, 2, 93-99. doi:10.1016/S1097-2765(00)80117-3

[19] Levy-Rimler, G., Viitanen, P., Weiss, C., Sharkia, R., Greenberg, A., Niv, A., Lustig, A., Delarea, Y. and Azem, A. (2001) The effect of nucleotides and mitochondrial chaperonin 10 on the structure and chaperone activity of mitochondrial chaperonin 60. European Journal of Biochemistry, 268, 3465-3472. doi:10.1046/j.1432-1327.2001.02243.x

[20] Mizuno, K., Tsujino, M., Takada, M., Hayashi, M. and Atsumi, K. (1974) Studies on Bredinin. I. The Journal of Antibiotics (Tokyo), 27, 775-782. doi:10.7164/antibiotics.27.775

[21] Terai, C., Hakoda, M., Yamanaka, H., Kamatani, N. and Kashiwazaki, S. (1995) Differential cytotoxic effects of mizoribine and its aglycone on human and murine cells and on normal and enzyme-deficient human cells. Biochemical Pharmacology, 50, 1099-1102. doi:10.1016/0006-2952(95)00232-O

[22] Hirohata, S., Nakanishi, K. and Yanagida, T. (2000) Inhibition of cyclin A gene expression in human B cells by an immunosuppressant mizoribine. Clinical and Experimental Immunology, 120, 448-453. doi:10.1046/j.1365-2249.2000.01242.x

[23] Stypinski, D., Obaidi, M., Combs, M., Weber, M., Stewart, A.J. and Ishikawa, H. (2007) Safety, tolerability and pharmacokinetics of higher-dose mizoribine in healthy 
male volunteers. British Journal of Clinical Pharmaco$\log$, 63, 459-468.

doi:10.1111/j.1365-2125.2006.02779.x

[24] Tanaka, H., Tsugawa, K., Suzuki, K., Nakahata, T. and Ito, E. (2006) Long-term mizoribine intermittent pulse therapy for young patients with flare of lupus nephritis. Pediatric Nephrology, 21, 962-966. doi:10.1007/s00467-006-0120-8

[25] Itoh, H., Komatsuda, A., Wakui, H., Miura, A.B. and Tashima, Y. (1999) Mammalian HSP60 is a major target for an immunosuppressant mizoribine. The Journal of Biological Chemistry, 274, 35147-35151. doi:10.1074/jbc.274.49.35147

[26] Motojima, F., Makio, T., Aoki, K., Makino, Y., Kuwajima, K. and Yoshida, M. (2000) Hydrophilic residues at the apical domain of GroEL contribute to GroES binding but attenuate polypeptide binding. Biochemical and Biophysical Research Communications, 267, 842-849. doi:10.1006/bbrc. 1999.2020

[27] Agboola, F.K. and Okonji, R.E. (2004). Presence of rhodanese in the cytosolic fraction of the fruit bat (eidolon helvum) liver. Journal of Biochemistry and Molecular Biology, 37, 275-281. doi:10.5483/BMBRep.2004.37.3.275

[28] Machida, K., Fujiwara, R., Tanaka, T., Sakane, I., Hongo, K., Mizobata, T. and Kawata, Y. (2009) Gly192 at hinge 2 site in the chaperonin GroEL plays a pivotal role in the dynamic apical domain movement that leads to GroES binding and efficient encapsulation of substrate proteins. Biochimica et Biophysica Acta, 1794, 1344-1354.

[29] Martin, J., Langer, T., Boteva, R., Schramel, A., Horwich, A.L. and Hartl, F.U. (1991) Chaperonin-mediated protein folding at the surface of GroEL through a "molten globule"-Like intermediate. Nature, 352, 36-42. doi: $10.1038 / 352036 \mathrm{a} 0$

[30] Rye, H.S., Roseman, A.M., Chen, S., Furtak, K., Fenton W.A., Saibil, H.R. and Horwich, A.L. (1999) GroELGroES cycling. Cell, 97, 325-338. doi:10.1016/S0092-8674(00)80742-4

[31] Koike-Takeshita, A., Yoshida, M. and Taguchi, H. (2008) Revisiting the GroEL-GroES reaction cycle via the symmetric intermediate implied by novel aspects of the GroEL(D398A) mutant. The Journal of Biological Chemistry, 283, 23774-23781. doi:10.1074/jbc.M802542200

[32] Teh, C.E., Daley, S.R., Enders, A. and Goodnow, C.C. (2010) T-cell regulation by casitas B-lineage lymphoma $(C b l b)$ is a critical failsafe against autoimmune disease due to autoimmune regulator (Aire) deficiency. Proceedings of the National Academy Sciences of the USA, 107, 14709-14714. doi:10.1073/pnas.1009209107

[33] Pfister, G., Stroh, C.M., Perschinka, H., Kind, M., Knoflach, M., Hinterdorfer, P. and Wick, G. (2005) Detection of HSP60 on the membrane surface of stressed human endothelial cells by atomic force and confocal microscopy. Journal of Cell Science, 118, 1587-1594. doi:10.1242/jes.02292

[34] Pockley, A.G., De Faire, U., Kiessling, R., Lemne, C., Thulin, T. and Frostegard, J. (2002) Circulating heat shock protein and heat shock protein antibody levels in established hypertension. Journal of Hypertension, 20, 1815-1820. doi:10.1097/00004872-200209000-00027

[35] Xiao, Q.Z., Mandal, K., Schett, G., Mayr, M., Wick, G., Oberhollenzer, F., Willeit, J., Kiechl, S. and Xu, Q. (2005) Association of serum-soluble heat shock protein 60 with carotid atherosclerosis. Clinical significance determined in a follow-up study. Stroke, 36, 2571-2576. doi:10.1161/01.STR.0000189632.98944.ab

[36] Itoh, H., Komatsuda, A., Ohtani, H., Wakui, H., Imai, H., Sawada, K., Otaka, M., Ogura, M., Suzuki, A. and Hamada, F. (2000) Mammalian HSP60 is quickly sorted into the mitochondria under conditions of dehydration. European Journal of Biochemistry, 269, 5931-5938. doi:10.1046/j.1432-1033.2002.03317.x

[37] O'Brien, R.L, Fu, Y.X., Cranfill, R., Dallas, A., Ellis, C., Reardon, C., Lang, J., Carding, S.R., Kubo, R. and Born, W. (1992) Heat shock protein Hsp60-reactive gamma delta cells: A large, diversified T-lymphocyte subset with highly focused specificity. Proceedings of the National Academy Sciences of the USA, 89, 4348-4352. doi:10.1073/pnas.89.10.4348

[38] Wucherpfennig, K.W., Newcombe, J., Li, H., Keddy, C., Cuzner, M.L. and Hafler, D.A. (1992) Gamma delta T-cell receptor repertoire in acute multiple sclerosis lesions. Proceedings of the National Academy Sciences of the USA, 89, 4588-4592. doi:10.1073/pnas.89.10.4588

[39] Yifrach, O. and Horovitz, A. (2000) Coupling between protein folding and allostery in the GroE chaperonin system. Proceedings of the National Academy Sciences of the USA, 97, 1521-1524. doi:10.1073/pnas.040449997

[40] Hoshino, M., Kawata, Y. and Goto, Y. (1996) Interaction of GroEL with conformational states of horse cytochrome c. Journal of Molecular Biology, 262, 575-587. doi:10.1006/jmbi.1996.0536

[41] Sameshima, T., Ueno, T., Iizuka, R., Ishii, N., Terada, N., Okabe, K. and Funatsu, T. (2008) Football- and bullet-shaped GroEL-GroES complexes coexist during the reaction cycle. The Journal of Biological Chemistry, 283, 23765-23773. doi:10.1074/jbc.M802541200

[42] Nojima, T. and Yoshida, M. (2009) Probing open conformation of GroEL rings by cross-linking reveals single and double open ring structures of GroEL in ADP and ATP. The Journal of Biological Chemistry, 284, 2283422839. doi:10.1074/jbc.M109.020057

[43] Kubo, T., Mizobata, T. and Kawata, Y. (1993) Refolding of yeast enolase in the presence of the chaperonin GroE. The nucleotide specificity of GroE and the role of GroES. The Journal of Biological Chemistry, 268, 19346-19351.

[44] Todd, M.J. and Lorimer, G.H. (1995) Stability of the asymmetric Escherichia coli chaperonin complex guanidine chloride causes rapid dissociation. The Journal of Biological Chemistry, 270, 5388-5394. doi:10.1074/jbc.270.10.5388

[45] Aharoni, A. and Horovitz, A. (1996) Inter-ring communication is disrupted in the GroEL mutant Arg $13 \rightarrow$ Gly; Ala126 $\rightarrow$ val with known crystal structure. The Journal of Biological Chemistry, 258, 732-735. doi:10.1006/jmbi.1996.0282 
[46] Llorca, O., Pérez-Pérez, J., Carrascosa, J.L., Galán, A., Muga, A. and Valpuesta, J.M. (1997) Effects of the interring communication in GroEL structural and functional. The Journal of Biological Chemistry, 272, 32925-32932. doi:10.1074/jbc.272.52.32925

[47] Miyazaki, T., Yoshimi, T., Furutsu, Y., Hongo, K., Mizobata, T., Kanemori, M. and Kawata, Y. (2002) GroELsubstrate-GroES ternary complexes are an important transient intermediate of the chaperonin cycle. The Journal of Biological Chemistry, 277, 50621-50628. doi:10.1074/jbc.M209183200
[48] Takahashi, S., Wakui, H., Gustafsson, J.-A., Zilliacus, J. and Itoh, H. (2000) Functional interaction of the immunosuppressant mizoribine with the 14-3-3 protein. Biochemical and Biophysical Research Communications, 274, 87-92. doi:10.1006/bbrc.2000.3104

[49] Kawasaki, Y. (2009) Mizoribine: A new approach in the treatment of renal disease. Clinical and Developmental Immunology, 2009, Article ID: 681482. doi:10.1155/2009/681482 